division of the muscle, and the danger, at the same time, of its being thrust into the eye during any sudden resistance of the patient.

To lessen these difficulties and dangers, $I$ beg to suggest to the profession the use of a knife, which has afrorded me the utmost facility in effecting a speedy and clean division of the muscle close to its insertion. It possesses all the properties of a scalpel; namely, utility, effectiveness, and safety, iv a smaller space than any other instrument with which I am acquainted, that has been adopted for dividing the internal rectus muscle. The blade consists of two parts; a rounded portion resembling the blunt part of a hernia knife, and a small, sharp, flat extremity, having a transverse cutting edge, which at one end terminates in a shoulder, by uniting with a short, sharp, front edge, while its other extremity forms a point by meeting the black edge at right angles; so that we have the transverse effective part of the blade in immediate connection with the useful shoulder and point. The annexed engraving is a correct representation of the knife as made by Mr. Weiss.

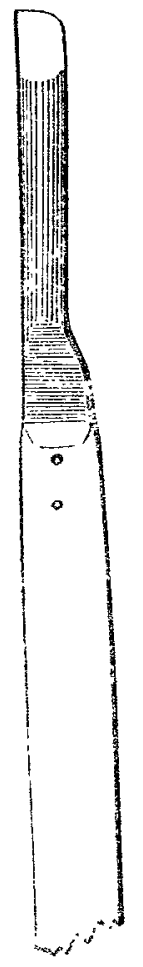

The instrument described cannot be thrust into the eye by any sudden accidental resistance of the patient; and this safety is owing to the position of its straight-cutting edge, which dues not require any sharp part of the knife to be directed towards the glube of the eye during any moment of the operation; the muscle being slightly raised across the blunt hook, its fbres are divided trans- versely by the knife, its edge being directed towards the hook, but at right angles to it, so that the flat side of the blade is held towards the eye. I am, Sir, your obedient servant,

27, New Broad-street, City,

JAMES J. ADAMS. Aug. 27, 1840.

\section{CRACKED TONGUE.}

\section{To the Editor of THE LANCEr.}

Srr:- Some time ago a country lad (aged 18) consulted me respecting "something that was the matter with his tongue." On examination, I could discover nothing unusual, excepting a deep groove, or crack, extending from the root to the apex; the edges of which groove or crack were somewhat elevated, rough, and irregular. The lad declared that he had suffered greatly from this affection during the last six or eight months; and that he had consulted several medical men, but had derived no benefit from their advice.

Of course, I looked to the stomach (the unfortunate organ to whose impertinence so many local diseases are speciously assigned) as the proximate cause of the lad's " bad tongue." Accordingly, I set about putting the digestive organs into " good order," and applied various caustics to the rart affected, \&c.; but at the end of two months the groove or crack in the tongue remained in statu quo.

The lad continued to call upon me until $I$ was really tired of seeing him, finding that not the slightest improvement took place in his tongue. I have never seen a similar case, nor have I found it described in buoks: I was much struck, therefore, with the folm lowing remarks in the "Memoirs of Charles Mathews:"-_ In a few weeks (says Mrs. M.) after these harassing struggles, my hus. band found an occasional inconvenience, that he had lately felt, augmented to a most serious disorder, his eventual sufferings from which were truly pitiable. I can only describe it by saying, that it showed itself in deep cracks across his tongue. Every advice was sought and attended to; but it baffed the first-rate skill and experience. It sometimes prevented him from eating, and banished sleep; and had he not been resolute in the prosecution of his duty, he must have declared it (as his medical men did) impossible to use it professionally. Every word he uttered was like a drop of aquafortis upon these cracks. This complaint had in turn been pronounced to be stomach and local fever, caused by anxiety and his great professional exertions. On the days of performance he often found it requisite to preserve a total silence until he began bis " entertainment," when he described his sensations to be like what he must be sup- 
posed to feel while talking and singing with a piece of red-hot iron attached to his tongue."

Now, Sir, one does not feel much surprised that the extraordinary man whose facetious volubility caused half the town to " crack" their sides with laughter, should in his turn get a "crack" in his tongue; but one cannot fail to remark, 1st, the great sinilarity between the two cases; and, 2ndly, the failure in both of the methodus medendi. I am, Sir, your obedient servant,

23, Upper Seymour-street West, S. Godson, M.D. Connaught-square, August 26, 1840.

\section{CASE OF SEVERE RHEUMATISM CURED BY NATURE.}

\section{To the Editor of The LANCET.}

Sir :-I beg to send you some statements under the above head. Much benefit would, in my opinion, accrue to medical men, if patients themselves more frequently laid before the public a statement of the effect upon them of medicines administered to them, and of the efforts of nature to restore them to health. It is from this conviction that $I$ beg to explain here the mode in which $I$ have recovered from a violent rheumatism.

During the winter of $1838.9, I$ was, for the greater part of the day, engaged in writing, and being generally very sensible to draughts of air, I took, indeed, care to keep the win. dows and the doors of my sitting-room shut; they closed, however, not quite, as is the case in the generality of the houses in London, and being obliged, for having a fire, to remove the chimney-board, there was al ways some draught in my room; in addition, a general draught was kept up in the house in which $I$ then resided, and the whole site of it, Covent.garden Colonnade, was itself much exposed to draughts of air, as six or eight streets and lanes open on it. The whole of the day, when $I$ was writing, the draught of air passed by my left side, and at the end of the winter I felt some difficulty in walking, but thought it would go off by itself, and took no medicine. In the ensuing spring, however, and summer of $1839, \mathrm{my}$ complaint increased, when it became clear that nature could not cure it, unless assisted by external or internal medicines, or a change of my residence. When I next took the advice of medical gentlemen; one deem. ed an aperient necessary, the other an em. brocation. To an aperient $I$ objected, ny complaint being of six months' standing, and having been in this manner ulmost incorporated in the system; in fact, German physicians never administer aperients in chronic diseases, as one or two would, at all events, not be sufficient, and a protracted treatment of this kind could only tend to delay the recovery of a patient. I then resorted to the embrocation prescribed for me, and con. sisting of a camphorate ointment; I rubbed with it the left hip and thigh, also the extremities of the left ribs; but though it first seemed to relieve me, it finally increased the difficulty which I found in walking, and the soreness of the region of the extreme left ribs. Probably the embrocation, which 1 continued for upwards of a month, was too strong for me, ammonia being added; I re. member also having read in Germany, in 2 medical journal, that it was a prevalent error to suppose that rhe u matic swelling of cheeks could be cured by the application of cushions flled with camphor, which rather protracted the evil, as the camphor more con. densed the rheumatic substances than dis. persed them. A milder embrocation of opodel. doc seemed at first to have a good effect ou my complaint; but it was of too long stand. ing to be cured by external means only. The principal difficulty was to get rid of what the modern medical school of Hahnemann now calls by a word from the Greek, "the psora,"i.e., the injurious matter affecting the internal parts and causing the illness; in my case the psora was the diseased rheumatic matter inducing a partial lameness of the muscles, on which walking depends, so as to create difficulty in walking, and soreness of the parts over the left hip. Now, in this country, they put great confidence in colchicum, whose use is in Germany more contined to gout ; it was, consequently, administered also to me, but weakened me generally, and my knees particularly, so that $I$ discontinued the pills in which it was made up, after baving taken them for upwards of six weeks, and never experienced any benefit from them.

A bout this time I saw in a London paper an article, the author of which stated, that aconite was in Germany now much administered in rheumatisms, and that he himself a graduate in medicine, who also gave his name, had cured a desperate case of this kind, by prescribing "extract of aconite a quarter of a grain twice a.day, gradually increased to six grains per day, to be taken with ten grains of Dover's powder." I began with Dover's powder, which I found to have a general invigorating effect, without particularly acting on my complaint. Of the aconite $I$ then took in pills a quarter of a grain once a-day, but not twice, neither increasing the doses. This I found to strengthen the muscles, and I at one momeut thought I should entirely recover by it. I continued these pills for about six weeks, and might then have left the remainder to nature, and the after effect of the pills. Because, however, in the London paper, a medical practitioner had stated that six grains might be taken per day, I thought there wonld be no harm in continuing to take half a grain per day. No sooner had I taken this quantity on two 